\title{
A learning society by Dr Louise Pryor: Institute and Faculty of Actuaries Presidential Address 2021
}

\section{Friday 25 June 2021}

Ms. Annette Spencer: Hello and welcome to this year's Institute and Faculty of Actuaries (IFoA) Presidential address. My name is Annette Spencer and I am the Director of Public Affairs and Research at the IFoA. Today, I also have the job of introducing the IFoA's new President, Louise Pryor.

Louise has had a very varied career as an actuary, software engineer and academic and worked in diverse organisations, ranging from small tech start-ups to the Financial Reporting Council. Today, Louise works as an independent consultant in the areas of software, risk and sustainability. She is also chair of the London Climate Change Partnership and a non-executive director at the Ecology Building Society. Louise has a degree in mathematics from Cambridge University and a $\mathrm{PhD}$ in artificial intelligence from Northwestern University. She became a Fellow of the Institute of Actuaries in 1987 and has been involved with IFoA working parties and various other volunteer groups, off and on since 2002. She was first elected to the IFoA Council in 2015 and as President Elect in 2020.

Dr L. M. Pryor, F.I.A.: Thank you Annette (Spencer) and hello and welcome to you all. Although it is unfortunate in some ways that we cannot be together in Staple Inn, the advantage of being online is that so many people from around the world are able to be here - around 30 countries are represented. Although I cannot see you, I am pleased that many colleagues, friends and family have been able to make it.

It is an enormous honour to be chosen as president of the IFoA, an organisation with a long history, a global reach and an ambitious strategy. Over the past year, I have had the pleasure of working on the presidential team with John Taylor and Tan Suee Chieh as the executive have started to deliver Council's strategy for 2020 to 2024. I look forward to working with Tan Suee Chieh and Matt Saker over the next year as we continue this work.

There is a widespread view that we are living in a period of great change. Indeed, this has been a theme of many recent presidents in their addresses. Today, I am going to give you my perspective on that theme and argue that in order to survive and be sustainable, we as actuaries and the IFoA as an organisation, must keep learning.

Last year, in his address, Tan Suee Chieh argued that we should revive the spirit of a learned society and bring thought leadership to the foreground. I believe that in order to do that, and indeed in order to implement the IFoA's strategy of supporting our members to adapt to change in their existing fields of work, as well as moving into wider fields, we also need to be a learning society. I asked some actuarial friends what they consider have been the major changes over their careers. Here is a selection of their responses:

- Complexity, documentation and regulation.

- We have become also more digital and paperless, and we can more efficiently manipulate large volumes of data.

\footnotetext{
(C) Institute and Faculty of Actuaries 2021. This is an Open Access article, distributed under the terms of the Creative Commons Attribution licence (http://creativecommons.org/licenses/by/4.0/), which permits unrestricted re-use, distribution, and reproduction in any medium, provided the original work is properly cited.
} 
- Lots of change in the area of mathematical and actuarial developments combined with more sophisticated modelling tools, data analytics.

- A definite shift in focus, all long-term strategy discussion and end-game planning in the pension industry.

- There are now fewer actuaries at the upper echelons of major insurance organisations, than in the 1980s and through the 1990s.

- The biggest change was the reduction in interest rates from around $10 \%$ per annum to nearly zero now.

- It is climate change and sustainability that have just accelerated up the agenda. Probably fuelled by some regulatory interest and the need for urgent action across business and society.

- One of the biggest changes is the beginning of diversity within the profession. There is still a long way to go, but it has been amazing to witness the start of it.

Many of their points chime with my own experience. Although the IFoA in its current form dates only from 2010, it has a long history. It is the result of a merger between the Institute of Actuaries, founded in England in 1848 and the Faculty of Actuaries, founded in Scotland in 1856. There were 70 Presidents of the Institute, 60 of the Faculty, and I am the twelfth President of the IFoA. Allowing for repeat offenders, that makes me the 139th president in all. I do not have detailed information, but without doubt nearly all the 138 previous presidents worked in either life insurance or pensions. Twelve of them have been called John and eleven William, but I am only the fourth woman and only two presidents have been based outside the UK. It has not been a very diverse group.

I am thus atypical. In fact, I am atypical in several ways. Not only am I a woman, but my career history has been far from standard. So, I will start by describing my career so far and the changes that have occurred along the way.

\section{1-1988 A Traditional Actuary}

I became a student of the Institute of Actuaries in 1981. I had studied maths at university and was hired as an actuarial analyst by a firm of pension consultants. This was in spite of being advised by the university careers service to become a teacher, which they suggested to all women studying maths, and in spite of being told by a partner of one of the largest consultancies that they had never had a woman qualify with them.

I am pleased to report that I made rapid progress through the exams. However, I turned out to be fairly unenthusiastic about pensions, so I soon moved employers to start working as a consultant in life insurance. I finished the exams in 1985, becoming an Associate and around then moved into general insurance. I became a Fellow in 1987 when I completed the two years of experience that were then required.

Probably the most significant change during this period was the advent of personal computing. When I started out in 1981, we had no PCs. We did use computers for pension fund valuations and then for modelling life offices, but had to use special terminals to connect to them and there were no interactive applications such as spreadsheets, so all the programming was in FORTRAN. By the end of the decade, spreadsheets were widely used for many routine calculations. For those of us working in life insurance, other changes were afoot. An increasing proportion of new business was unit linked rather than with profits, a development that was part of the long-term transfer of risk from institutions to individuals that we have seen over the last half century. It was also a development that was ignored in the exams.

Also in this period, the control cycle, that current exam, was introduced to unsuspecting actuaries in a paper to the Students' Society, the precursor of the Staple Inn Actuarial Society. As well 
as all the traditional actuarial techniques, I was learning about what went on in practice in the life insurance industry and then in general insurance. I was also learning a lot about computer programming. Although I had been programming since my early teens and had always enjoyed it, this was when it really took hold of me. This was to prove a significant development in the coming years.

\section{8-2002 An Undercover Actuary}

In 1988, I changed direction rather more radically. I went off to the States to study for a PhD in Computer Science, specialising in artificial intelligence. I loved my five years in graduate school, it was a great time. Being a full-time student again, but this time with added time management skills, was enormous fun. I came back to the UK in 1993 and was a university lecturer for three years before deciding that academia was not for me. I went into the software industry, working for startups. This was during the dot com boom and it was an exciting time, if somewhat precarious when the inevitable bust followed the boom.

At the turn of the century, I was hired by a start-up, analysing financial risk. The technicalities of actuarial work had changed significantly in my absence. The world was full of new terms such as stochastic modelling, value at risk, economic scenario generator, asset liability modelling and option pricing approaches. I did some rapid learning. Mark to market had also more or less completely taken over. At the end of the 1980s, many pensions actuaries had still been using the so called actuarial value of assets, calculated by discounting future cash flows, but now market values ruled. Another change was the growth of risk management as an explicit skill set. And spreadsheets were by now all pervasive.

Many of these changes had started in the 1980s, but had gathered pace in the 1990s. The rate of change was distinctly non-linear. Stochastic modelling, for example, had first been introduced in the context of maturity guarantees in 1980, but only became mainstream ten to fifteen years later. In the 1980s, the adoption of technology had really been about automating existing analyses and speeding them up; in the 1990s, we were seeing that automation allowed us to do things we simply had not been able to do before. E-mail had been ubiquitous in academia in the late 1980s, certainly in computer science, and was in general use everywhere else by the end of the 1990s. Mobile phones also became mainstream at around this time. The World Wide Web was invented in 1989 and was widespread by the end of the 1990s. Importantly for actuaries, Equitable Life ran into problems with its guaranteed annuities, losing a case in the House of Lords in the year 2000.

As I have said, for some of this period I was in academia, first as a student and then as faculty, so learning was high on my agenda. I learned a lot more about computer programming and computer science - by no means the same thing - and about software engineering. My time working for start-ups also brought home to me the importance of business models and strategy, and above all the importance of cashflow.

\section{2-2011 A Non-Traditional Actuary}

In 2002, I was made redundant and decided that it was time to get out of the uncertain world of software start-ups, so I moved to the uncertain world of freelancing and set myself up as a software risk consultant. The idea was that I would consult to actuaries and others about how they used and developed software, with a special emphasis on spreadsheets. I started networking frantically and found that the best, and by far the most enjoyable, way to do it was through the actuarial profession. I went to GIRO and joined working parties, as well as finding my way onto various committees for the Finance and Investment Board and professional standards. 
At this time, the way the UK actuarial profession was organised was changing. The near collapse of Equitable Life at the turn of the century had led eventually to the Morris Report, which contained some fairly trenchant and widely shared criticisms of actuaries, and recommended that the Financial Reporting Council (FRC) should oversee the actuarial profession and set technical standards. In 2007, my domestic circumstances changed and I moved back down south from Edinburgh where I had spent eleven very happy years. By then, the FRC had established its actuarial function and when I decided I needed to get a proper job that is where I ended up. I started out as their general insurance specialist, but then became Director of Actuarial Standards, leading the team that developed the technical actuarial standards, or TASs. These were among the most interesting and rewarding years of my career. I learned about the full range of actuarial work, as well as about professional regulation. I found that writing standards has many similarities to computer programming - you must always keep the top-level goal in mind, but it is really important to get every tiny detail exactly right. There was also the fun of construction, of building something, which is also true of programming.

It was also an interesting time because the actuarial world was still changing quite rapidly. The main drivers were regulation and the increased availability of processing power and data storage. These combined to fuel the increasing dominance of risk based capital, and internal models for insurers.

Meanwhile, it had become evident that mortality rates in the UK were improving both rapidly and consistently. Actuaries had to change their approach to mortality projections. It had only been in 1999 that the CMI had first issued any projection factors for mortality rates. Those first factors depended only on age and gender, but in 2002 the CMI introduced a methodology for applying them to different cohorts. The first version of the CMI's stochastic projection model was only issued in 2010.

The reputation of the actuarial profession, which had already suffered as a result of the equitable crisis and the Morris Review, was badly hit by this perceived slowness to react. In many circles, our name was mud. Alongside all this, the 2008 financial crash changed the landscape and in 2010 the Institute and Faculty merged.

\section{2-2021 A Sustainability Actuary}

In 2012, the FRC completed the initial set of TASs and I returned to freelancing. I thought then, and still do, that climate risk is by far the biggest problem facing the world and wanted to do something to help address it. In 2013, I started to become heavily involved in what grew into the Sustainability Practice Board of the IFoA. Meanwhile, I was considering what freelance work I could do.

I knew a fair bit about modelling, was learning fast about climate risk and was interested in both of them. So that is what I have been doing for the last ten years or so, although I have not actually managed to combine them yet. The modelling work has mainly been concerned with pensions and social security reform in developing economies, while the climate risk work has mainly been looking at the impacts on insurance.

Along the way, I have acquired various other roles, most of which are not specifically actuarial, though I bring my actuarial background to all of them. For a few years, I worked with the Centre for Risk Studies at Cambridge, looking at emerging risks. I am involved in climate change adaptation through the London Climate Change Partnership and I am involved in sustainability in the built environment as a non-executive director of the Ecology Building Society and as an honorary professor at UCL's Bartlett School of Sustainable Construction. I also continue to learn about climate risk and sustainability through leading IFoA working parties.

The actuarial world carries on changing. Over the last ten years, we have seen data analytics become much more widespread as computing power and data storage capacity continue to grow. 
Quantitative risk and capital modelling are more dominant than ever. A number of risks have newly emerged as significant, including cyber and of course pandemic risk. The consideration of climate risk has become mainstream and even mandated by regulators in many countries.

Social media and blogs provide new ways of disseminating information. Video conferencing enables us to work with people regardless of their physical location, although time differences still cause problems. Meetings at three in the morning are no fun for anyone. In the last eighteen months, COVID-19 has accelerated ongoing changes and driven the introduction of new ones. The IFoA moved all its events and exams online in April 2020. We have developed new ways of working with volunteers through our COVID-19 Action Taskforce, or ICAT, which at its peak had around 90 work streams and 500 volunteers.

\section{Change}

I have seen huge changes over my career.

Interest rates are at the heart of much actuarial work. In the 1980s, they were both high and volatile, ranging between $9 \%$ and $15 \%$. Since 2008 , they have been low and stable, staying at under $1 \%$ for over twelve years now.

There has been a transfer of risk from institutions to individuals, exemplified by the growth of unit linked life insurance and defined contribution pensions in the UK.

There are new types of risk, such as climate risk, that simply were not on the horizon forty years ago.

Our techniques and models are much more sophisticated than they used to be.

There have been major changes in the IFoA too. It has grown. We now have over 33,000 members compared to 6,000 in 1981 . In 1981 , only $6 \%$ of us were women, now it is $36 \%$. When I became a student in 1981, there were fewer than 300 other women students of the Institute. In 1985, I became one of only around 60 women associates and in 1987 I joined a select group of fewer than 100 women Fellows of the Institute. There are now well over 4,000 women Fellows of the IFoA.

We now have a single professional body in the UK, instead of two. Many more of our members are based outside the UK. The organisation has had to learn how to operate on a completely different scale. It has had to learn how to do new things and use new tools, such as the web and social media.

All these changes mean that those of us who have been in the profession for longer than three or four years have had to learn new skills since we started. We cannot operate in today's world using yesterday's skillset. I asked some actuarial friends what they have learned over the course of their careers. Here are some of their responses:

- In my career today I have dabbled across various different fields and so in the process of that had to build up vast new skills each and every time that I have switched and changed.

- Generalised linear models.

- Starting as pensions actuary, after moving to Kenya, I have picked up skills in social security pensions and unemployment benefits and in advising insurance and re-insurance companies.

- Stochastic modelling.

- Definitely the most fun new skill I have learned was data wrangling in R. I would like to do more of that.

- Communication.

- Team leadership. Moving into a technology function and away from a traditional financial risk management role has helped me tremendously to understand business context at an operational level. 
- Negotiating skills.

- In my company, we are backing a long-term investment product using cattle. I have learned a lot about farming, about community relations with smallholder farmers surrounding our farm, who we work with. Also, mass media marketing as we promote our very innovative product.

- Also, influencing skills at management level.

- The biggest skill that I have learned is networking. I have networked with people through actuarial dining clubs, through sessional meetings and over the last eighteen months via Zoom, through webinars and so on.

This learning process, both individual and organisational, must continue and pick up pace if we are to remain relevant in the 21st century. One of the three key themes of the IFoA's strategy for 2020 to 2024 is centred on supporting members by developing their skills so they can adapt to change in their current fields of work, as well as moving into wider sectors. It is all about learning.

A major plank supporting the 2020 strategy is our Learning Change Programme, which aims to modernise, deepen and broaden the IFoA's actuarial qualifications and lifelong learning support. When I took the exams all those years ago there seemed to be a disconnect between the actuarial exams and what I spent my time doing in practice. Much of the exam content seemed to be a possibly pointless intellectual exercise. I may be exaggerating here, but not by much. This has always been a problem for the profession: how to keep exam syllabuses up to date and relevant, while not making life difficult for the students by changing them too quickly, or getting carried away by short-lived fads. The Learning Change Programme is currently reviewing the preassociate syllabus to ensure the curriculum reflects the needs of the IFoA students and their actual and potential employers. Some of the changes that will appear in the 2022 exams include more emphasis on both sustainability and banking - new skills and new fields of work.

The second strand of the programme is the development of a broader portfolio of routes to Fellowship. The first change from this strand will be the introduction of Fellowship exams on banking, which we're hoping to offer from 2022. Other possibilities that are being considered include data science and sustainability.

The third strand is around assessment methods. Over the last year, spurred by COVID-19, the IFoA has moved from paper-based, closed book exams to online, open book exams. This is a fantastic achievement and is the result of much hard work under intense time pressure from both executive and members. In the next couple of years, we are planning to provide wider access to all our students by moving to a new exam delivery system.

The final strand of the Learning Change Programme, which is central to the whole endeavour, is lifelong learning. I have already discussed why lifelong learning is so vital. Of course, the exams are important, but changing them affects only those who are still taking them. There are currently over 15,000 Fellows and Associates who cannot rely only on the skills that were tested when they took the exams towards the beginning of their careers.

We already have an extensive range of events put on by Practice Boards and Member Interest Groups. The programme is looking at how else our members can be supported. For example, there are two new lifelong learning microsites on the IFoA website, on banking and sustainability. The sustainability microsite includes a really useful and extensive annotated reading list. There is also a series of practical guides to climate risk for actuaries working in a range of practice areas.

There are new credentials too. In 2019, we introduced the certificate in data science, which now has over 330 graduates. Work on a credential on climate risk is well developed, with a pilot programme currently underway. If it is successful, we are hoping to be able to offer the full credential later this year.

The Learning Change Programme is not the only activity in the IFoA that is supporting continued learning by our members. For example, a new CPD scheme was introduced last year, which encourages us to take responsibility for our own learning needs, rather than simply ticking off the 
required number of hours and there is a lot of learning going on. I asked some of my actuarial friends what they are currently learning and here are some of their replies:

- How to integrate drought indices in social cash transfer programmes in Africa.

- Sustainability development.

- Behavioural science strategy, corporate social responsibility and many other areas.

- Transfer learning and the Bert Language Model.

- Biodiversity, which has been a fascinating topic.

- More about the history of some of the African countries where we have been living.

- How to use satellite risk models to apply for typhoon index insurance in the South Pacific.

- Rotating graduate programme to get experience in a new business area.

- Digital financial services in Africa and the synergies that they have with insurance services.

- Understanding the implications and risks of climate change and how that impacts on the insurance industry.

I have already described some of the changes that have occurred over the last 40 years. But change is continuous and still affecting actuaries and the IFoA.

Technological change, driven by the growth of computing power, is clearly important as it expands the techniques that are available to us. A number of our colleagues are specialising in data science, where there are enormous opportunities for people who can both understand the technical aspects and relate the models to the business world - people who understand that models are tools, not oracles. Technological change is also a driver of the explosion in communication channels that has occurred over the last 40 years. First, fax took over from telex, then e-mail and the web appeared, then text messages and now we have social media, instant messaging and video calls.

The IFoA is learning to embrace video conferencing, allowing many more of our members to participate in working groups and attend online events, including this one. The COVID-19 Actuaries Response Group has made excellent use of social media and online resources to build a reputation for timely and informed comment, both within and beyond the profession.

We hope that some of these new technologies will support us in providing different ways for our members to connect with each other and with the wider world. For example, we are currently operating pilot online digital communities for banking and data science and hope to be able to start more in the coming months.

Societal changes are equally important. Both diversity and sustainability risks have moved from the fringe to the mainstream. It is to them that I now turn.

\section{Diversity}

Society is placing a growing emphasis on diversity. This is very welcome. For too long we have drawn comfort from being surrounded by people like us and have failed to recognise the benefits that diversity brings.

I have already illustrated the growing proportion of women in the IFoA over the past 40 years, but it has been a slow growth. Half the current women Fellows have qualified since 2012, but only a third of the men. Ten years ago, $37 \%$ of our students were women, now it is still only $42 \%$. Even now, fewer than $30 \%$ of our Fellows are women.

However, this is only one aspect of diversity. I have focused on it partly because it affects me directly - there are only 50 women from my generation or earlier - and partly because we do have some statistics in the area. We also have statistics on how many of our members are based in the UK, but we have very few on other aspects of diversity. We are a profession founded on data and we have a big gap in this area. This must change. 
We need to do more to increase diversity within the profession so that we can tap into the full potential that is available to us. Not only do we need to work with employers and universities to ensure there are no unintended barriers to entry but we also need to make sure that we are supporting people from all backgrounds throughout their careers.

We have made a good start by removing formal entry requirements. The Learning Change Programme will help to ensure that our qualification structure focuses on the competencies that are required to be an actuary today and in the future, rather than on past experience. Our Diversity Action Group is helping us to move to a position where the IFoA offers all members the support they need and the volunteering opportunities they deserve, but there is much work still to do.

\section{Sustainability Risks}

Over the last few years, climate change has become increasingly visible as a source of risk and biodiversity is starting to become visible too. But it is important to realise that climate change itself is not a risk, it is a certainty. Climate change and biodiversity are both happening and are both being driven by human behaviour.

The risks are posed by the impacts of these changes. For example, potential impacts of climate change include severe weather events such as floods and droughts, mass migration, civil unrest and many others. They also include changes to consumer demand, business models, the financial system, the economy and regulations, all of which will directly affect actuaries and the users of their work. The impacts of climate change pose long-term risks with significant financial effects. They go to the heart of what we do. Ignoring climate change will not make it go away.

However, sustainability risks are in many ways quite different from the other risks that actuaries traditionally deal with, because of the deep uncertainty involved. There are intrinsic limits to predictability in complex systems and we are certainly dealing with very complex systems here.

Sustainability risks are not repeatable - they cannot happen over and over again. Instead, they are chronic and long lasting. Their impacts are systemic, wide ranging and may include fundamental changes to the economic and financial systems. We do not have direct historic data on the impacts because climate change and biodiversity loss to this extent simply have not happened in recent human history. We cannot derive probability distributions for them.

Moreover, the impacts of sustainability risks are irreversible. It is not possible to recover from them and return to the past position. Non-linearity and the existence of tipping points mean that there is no going back. We cannot restore species that have become extinct and we cannot refreeze icecaps that have melted within any reasonable timescales.

All these characteristics mean that we do not know how to calculate the cost of these impacts. What is the monetary value of a fundamental change in how our world operates?

So there is a major risk management challenge. How can these risks be managed? And they must be managed at many different levels. We must manage them at the global and societal levels, but insurers, pension schemes and other organisations have to manage them too. And global systemic risks like this cannot be hedged.

But what has all this got to do with actuaries? Or to do with learning? As you might have guessed, the answer is "a lot" in both cases.

First, climate change poses significant financial risks to insurers and pension schemes, our traditional employers and clients. We will be letting them down if we ignore those risks, which means of course that we must learn about them and about their potential impacts. If we don't, we will lose all credibility as a risk management profession.

Second, addressing this major societal risk management challenge requires new skills. This is a once in a lifetime opportunity for actuaries to use our unique insights, evolve our expertise and collaborate with other experts to help provide the new paradigms and methodologies that are needed. We have a head start as actuaries are currently very active in this area in the insurance 
industry. But the skills are needed everywhere, especially in banking where climate-related risks are near the top of the agenda for regulators in the UK and indeed globally.

And we need to up our game. We cannot rely only on quantitative methods of assessment for example, but will have to develop and extend our use of more qualitative methods such as scenarios and narratives. We will also need to make sure our models take account of the significant structural change that will affect the economic and financial systems.

We need to recognise that climate-related risks cannot be seen in isolation from other risks they arise from the complexity of the overall ecological, social and economic system that we live in. We must make more use of systems thinking techniques. We can only address the problems posed by climate change if we recognise their interactions with the diversity of human experience, and with both global and local inequalities.

Society must find a just transition to a low-carbon world that supports both society and biodiversity, one that seeks to ensure that the substantial benefits are shared widely while also supporting those who stand to lose economically. This is a very actuarial problem. Actuaries have been thinking about fairness and balancing the interests of different groups of people along varying timescales for nearly two centuries. It is a huge challenge, but also a major opportunity. If we ignore it, we will fast become irrelevant, side-lined as one of those quaint historic professions with no place in the world of the future. If we embrace it, we can help to lead society's efforts to create a better world.

Last year, the IFoA Council endorsed the report of its Climate Related Risks Taskforce, which has resulted in a major programme of work to ensure that IFoA members are equipped to deal with these challenges. All actuaries should be considering climate risk and other sustainability risks in the same way as they consider major risks such as interest rates and mortality. The Practice Boards have all developed engagement plans to raise awareness of how climate risk affects established areas of actuarial work and to provide support to their communities.

There are also several other groups who are addressing climate risk problems from a variety of perspectives. The Economics Member Interest Group is looking at how economic theories take account of sustainability issues. The Financial Systems Thinking Innovation Centre, or FinSTIC, is looking at how systems thinking can be applied to changing the financial system so that it delivers for society, the environment and the economy. The Actuaries' Carbon Collaboration is acting on climate solvency by working towards a coherent understanding of the issues around carbon emissions and offsets by considering them in an actuarial context.

These are all examples of the IFoA learning to work in new ways - groups led by actuaries, collaborating with others, with varying degrees of formality. We are working towards a much more open and facilitative culture where the IFoA can provide a platform for groups of thought leaders to come together and discuss interesting and provocative ideas. This is an area where technological developments can make all the difference. During this year, we have had several series of Thought Leadership events addressing such topics as Finance in the Public Interest, Actuarial Innovation in the COVID-19 Era, and Behavioural Science. In the coming year, you can expect more of the same, with a special focus on sustainability in the run up to COP26 this autumn.

At the beginning of this year, the IFoA issued a policy statement on climate change, supporting the aim of the Paris Agreement to limit climate change to an increase of substantially under two degrees Celsius from pre-industrial temperatures, and recognising that for there to be a reasonable probability of achieving this aim, there must be a transition to a global economy that has no net greenhouse gas emissions by 2050 . The IFoA will continue to work with national and supranational organisations to better align the financial system with a net zero ambition. But it is not only the IFoA which must play its part. All actuaries can also lead change in the financial system to serve the public interest in the management of climate related risk.

It is an enormous challenge, but also an enormous opportunity. Change can create new openings as well as closing old dead ends. There are opportunities for actuaries and also for the industries many of us work in. Financial institutions such as insurers and banks must ensure 
that their products and services actively drive the change that is needed for a transition to a net zero world and support people negotiating the rapidly changing risk landscape. And we actuaries can help them do that.

\section{A Learning Society}

I am proud to be an actuary. It has enabled me to have an extremely varied career and the actuarial skillset has proved to be a fantastic foundation for learning new skills and branching out into new areas. I am not alone in my view. I asked some actuarial friends what they enjoy about what they are currently doing. Here are some of their responses:

- I have loved my career, I really have. A lot of it is the people that you work with actually.

- I love the fact that I can use my actuarial skills in different ways that I had not thought possible before, to solve problems that I had not encountered before.

- These ideas will help develop safety nets for the millions of people affected by the food security and poverty issues that will come as a result of climate change.

- Having spent most of my life working for large, established companies, it has been exciting growing a new business.

- I am contributing in a small way to addressing some of the biggest challenges facing humanity and in doing so, helping to improve financial outcomes for pension scheme members.

- It is a tremendous opportunity to continue to learn. It is extremely worthwhile if not vital and I love working with people who think differently to me.

- I am looking for an adventure, I love learning, that is why I kept doing all those degrees and probably still have a few more to do. So, I absolutely love learning.

The times we are living in are challenging, to say the least. As I have discussed, change is all around us and in many ways change is uncomfortable. Change is affecting our traditional fields of work as well as opening up potential new fields. We have to be able to learn new skills in order to handle challenges as well as seize opportunities. We need a growth mindset to adapt to our changing world. Learning is absolutely vital to our wellbeing. The IFoA must learn as an organisation if it is to survive and must support its members' learning if they are to be successful. The sustainability of our profession depends on learning. As well as being a Learned Society, the IFoA must be a Learning Society.

The Moderator: Thank you very much Louise, I think you have followed in a long tradition of IFoA presidential addresses in giving us something which both inspired and challenged us. Now, what has come through in you address this morning, I think is the really clear sense of the issues which are going to be your focus during the coming year. We will now turn to the questions for the audience and give you the opportunity to respond.

\section{Questions from the audience and the President's Response:}

Questioner: In your address, you have talked about the way that you personally have constantly evolved and changed in your career and interests, and in particular of course the role of learning as a part of that. You also talked a little about sometimes the uncomfortable aspects of change. So, the question is, what is the advice that you would give to help anyone welcome change rather than resist it? Do you have a trick for how you overcome any discomfort you have from change?

Dr Pryor: Change is uncomfortable, the fear of the unknown. But maybe you can recast that as a love of the familiar. On the other side of the coin, there is the fear of missing out. You could recast it as the fun of discovery or maybe you can think about a lack of change as boring, as a lack of challenge. But I think the thing I have found is that actually the new world, the change, is not as strange, not as unknown, as you think it is going to be. There is usually a surprising number of 
things that carry on over from one situation to another. I have found in my career that it is very easy to get locked into your current world. So, for example, I did a $\mathrm{PhD}$ and then I was a junior lecturer for some years, and that was what was expected of academics. That is the career progression. You feel, well, that is what I do and that is what successful academics do, so if I do not do that I am not successful.

But you need to step out of that and realise that actually there is more to life than just that particular little closed world. That sounds demeaning to academia and I do not mean that at all. But more to that world, more to life than that way of doing it. My regrets, I think, have mostly been around not moving on soon enough. Staying with things that I thought were acceptable at the time, if not perfect, but then I changed and I found that what I thought was acceptable was not actually nearly as good as you could get. So, yes there is a factor of bravery, of being prepared to go out and try new things, but the other thing is that just because you make a change, does not actually necessarily mean that you have to stick with that change. You could change back, change another thing. Very few things are completely irreversible in this respect.

Questioner: It was really exciting to hear about banking and climate change hopefully coming along and joining the one that we already have on data science. So, do you have any more detail about what might be on the curriculum for these courses, and where and when might people expect to be able to find out more? Also, is there a plan to make data science a pathway to Fellowship?

Dr Pryor: Yes, I will take the pathway to Fellowship first. It is something we are exploring. We have to look at whether we think sufficient people would be interested in taking it and we also have to look at whether we have got the resources to support it. One of the things about our Fellowship exams in particular is that they rely on a lot of our members to help develop the curriculum, and in particular to set and mark the exams. We need to make sure that we have got people who will be able to do that.

Now let's take the other credentials. So, the banking Fellowship exams are already on the website: the curriculum for 2022, in the Banking Life Long Learning microsite. There are two Fellowship exams that we are proposing. The specialist principles exam will cover the key principles of banking; the clue is in the name there. It will be about what the main products are, basically how banks operate and the main risks in banking. We definitely need to recognise that this is where we focus, on risks. The specialist advanced level should enable you to contribute to, in a bank, to risk management and capital management, both of which of course actuaries do in insurers, and liquidity management, which is much more important in banking than in insurance. It will also cover strategy and understand the governance around all these. So, you can go to the website and look at that.

The climate change credential is still in pilot. We have not published anything on it yet. Basically, how we proceed from here depends on how the pilot goes. We are actually piloting both new content and a new way of delivering a credential. We are trying new things. If it does not work, we are going to have to think again, as I said before. The pilot covers just over half what we think the total content might be. It covers things like the physical and transitional impacts of climate change, who the stakeholders are, including super-national organisations like the UN and the intergovernmental panel on climate change and what their roles are. It covers financial regulation and financial disclosure. It covers the TCFD recommendations and that sort of thing. There is a module on economics and how economics can take account of climate change. There is a module on inequality, how climate change affects different people, different groups of people, different countries in different ways. I cannot, unfortunately, give you a firm timetable for this because it depends on the pilot. But so far, so good. I think we are all optimistic and hopeful that we might be able to offer something later this year.

Questioner: How big do you think the vacuum is in banking for actuaries to fill? Is there any particular expertise that actuaries can bring to the banking world? 
Dr Pryor: Yes, I think the particular expertise that actuaries can bring is this focus on long-term risks. In banking traditionally the risk management has really been fairly short-term. It is something I have learned in the building society that I have something to do with, that on the whole the emphasis is much more short-term than in say a life insurer. But something like climate risk is very long-term. It has effects ranging over timescales from one to two years, through to many, many more. I think that is a perspective actuaries can bring. Also, actuaries, or good actuaries, are very good at relating these risk ideas to a business context. So, not just looking at the numbers, not concentrating just on the numbers, but looking at the qualitative effects too. I think that basically in banking there is a bit of a vacuum because nobody has been doing this and they need to learn new skills, so that if they can import some actuarial skills that would certainly, I think, benefit banks, but it would also benefit our members as well.

The Moderator: Yes, that makes a lot of sense. I think the sectors that traditionally our members have worked in, but also areas like banking. They are experiencing change as rapidly and sometimes as uncertainly I suppose as we are, so you are right. Actually, the skills that actuaries bring in helping to apply that and helping to understand that, I can see how that would really fill a vacuum in banking. I hope that that answers that particular question that came in.

I am going to move us on to another theme of your address. You talked throughout the address really about the rapid changes going on in what I will call the digital world over the past few decades. It actually made me think a little bit about earlier this week when we had the President of the Royal Society, Sir Adrian Smith, speaking in the Thought Leadership series. He similarly talked about the developments and changes that are coming through with artificial intelligence and the relationship between $\mathrm{AI}$ and judgement. The question is what do you see as the main threats and the biggest opportunities, so threats and opportunities, for actuaries from these rapid changes in the digital world and AI?

Dr Pryor: The main threat from AI is that, I guess, we ignore it; that we do not embrace it, we do not take advantage of the opportunities. That we get reduced to just being people who do the numbers, who run AI models without really understanding what is going on, and just believe the numbers that come out of the model. We have to remember that AI is a tool. It is a part of what goes into making decisions. We need to be able to contribute to that and we can, by understanding how the AI models work. Some of us will do it at a very technical level, others will do it at a more conceptual level, but understanding what the assumptions that go into them are, what some of the implications are. It gives us an opportunity to step up and see the bigger picture. AI runs on data, but not all information can actually be codified and fed into AI systems, especially when you are thinking about the future. We do not have data about the future, because it has not happened yet. AI is very good at talking about how you can explain what happened in the past, how you can project the future if you expect it to stay roughly like the past. But if it is going to change a lot, then the AI results need to be treated with respect, but also with caution, with thinking about how they might or might not apply.

Overall, numerical models are part of the information that is needed in order to make decisions, but not all the information. As I said in my address, they are tools, not oracles. You can compare spreadsheets if you like. In the 1980s, there was a huge fear that actuaries would be put out of business by spreadsheets. It is easy for us to laugh now, when spreadsheets are such a major tool of what we do. So, I think we should think of AI as an opportunity, as a tool that will enable us to do more. To help us to spot new patterns that we had not been able to spot before, but AI won't necessarily tell us what to do about them. Just another quick thing, as many of us always say, correlation is not causality. Just because we have got a pattern, it does not mean that it is actually telling you about the reasons behind what is going on. So, I think it is a huge opportunity.

The Moderator: That's great Louise. I love again the positivity in that, particularly the idea that there will be always be a role for human and actuarial judgement. I guess, to see the machines as our friend and our tool, but as something that we can use to help us, rather than the other way 
around. That is, again, very inspiring. We are as you might expect getting a lot of questions in about climate, climate risk, climate change and so on.

Questioner: Climate scenario analysis is highly relevant at the moment with the Bank of England and the Network for Greening the Financial System publishing scenarios for financial institutions to use. How could actuaries use that and what should our role be? How can we use this as an opportunity to have greater influence over policy?

Dr Pryor: The first thing is that we have to be better at working with other people. I think we have to collaborate. We have to recognise that we have undoubted skills and insights, but so do other people. We must collaborate with others, especially climate scientists for example. I think I am going to focus mostly on scenarios in this question, because it is a peg that I can hang things off. We need to understand how realistic scenarios are and sense check them. I think this is actually a huge contribution we can make. For example, if there is a range of scenarios that people are suggesting we use, how different are the assumed impacts in the different scenarios? Does that make sense, are they different enough? Are they what you would expect? Do they allow for interactions between ecological and economic systems? For example, the NGFS assume a continuation of current economic and population trends. Is that plausible, basically? We have to think about those sorts of things. For some cases, we have to use the scenarios that we are given, for regulatory purposes for example. If regulators want us to use particular scenarios we have to use them, but they may not be suitable for all purposes.

I think one thing we have learned over the last year or so about scenarios is that sometimes we are not good enough of thinking of scenarios that are extreme enough. The extent of the disruption that was caused by COVID-19 was foreseen by some people, but there were very many people who did not. We have learned a bit more about unexpected effects and the extent of systemic impacts. The other thing about scenarios is that they are meant to be plausible, but they need not necessarily be likely. The one thing we do know about any given scenario is that it is not going to play out exactly like that. But plausibility is really important. Some scenarios that we are seeing are extremely unlikely. Again, the NGFS disorderly delayed transition assumes that nothing really happens until 2030: that nothing changes until 2030. But global warming is still kept under two degrees. That, to my mind, is extremely unlikely. It would require massive financial, economic and social change in an extremely compressed timescale. Believing that it is very likely could give a false sense of security. It is possible, but it would take an awful lot to make that actually happen. The Hothouse Earth current policy scenario, that the NGFS uses, results in global warming of only three degrees if we do nothing, if we carry on along our current path.

Most current evidence is that it is extremely likely that doing nothing would lead to irreversible global warming, well beyond three degrees. So, are scenarios like this giving a false sense of security? As actuaries, we need to think about the big picture as well as the detail. We need to consider the worst that can happen as well as the best. Actuaries do think about what the most likely path is, but as risk management professionals, we have to consider the whole range of outcomes. We must help ensure that our employers and clients, and indeed society at large, are not lulled into a false sense of security. We should use our professional skills, collaborating with other experts, to make sure that we really understand the underlying assumptions and how plausible and likely scenarios are.

Moderator: We now have some technical questions.

Questioners: You talked in your address about various changes through time and mark to market being something that you noticed when you came back into work after you had been in academia. The question is do you think mark to market was beneficial for long-term entities? If so, why? What's our unique insight in this area as actuaries? Some other professionals think that the actuarial profession lost its way at the time of the Black-Scholes revolution. That passed the profession by and the question is, do you think we can reclaim the lost ground in financial mathematics? 
Dr Pryor: This is not my specialist area, I have to say that. It is actually not clear I really have a specialist area in many ways. I think of myself as a generalist. But if I did have a specialist area, this would not be it. So, what I am going to do is to essentially talk as an outsider and so take everything I say with a slight pinch of salt. Mark to market, is it beneficial for the long-term? I have concerns about mark to market. If you take something like a pension scheme, the aim of the pension scheme, and indeed long-term life insurance business, the aim is to pay the liabilities as they fall due over the next, I don't know, it could be twenty, 30, 40, 50 years. Mark to market assumes that the market reflects a lot of what is known about the future. It also, if you are comparing the liabilities with the assets and the assets are taken at market value, it assumes that the liabilities are valued, if you like, consistently with those assets. I do not want to go into detail because as I say I am not an expert, but as an outsider I find some of these assumptions quite difficult to swallow. I find it quite difficult to think that there is a deep and widely traded market in pensions and liabilities that essentially operates in the same way and on the same basis as the assets market for example. So, has it been beneficial?

I think it has been beneficial in that it does provide a connection to the real world. Market values are what you could get for your assets now, but I think it has been less than beneficial in that in some sense what you can get for your assets now does not actually say how good they are going to be at meeting the liabilities over a 20-, 30-, 40-year period, as they come due.

What is our unique insight? I don't know. I always feel that it is partly about stepping back and seeing the big picture and saying, "What are you really trying to do here?" and providing the mathematical basis and understanding how that fits into the real world. Did we lose our way because of Black-Scholes? Can we reclaim our position? I think we can possibly reclaim a different position. I always get wary when people say, “Oh, wasn't it fantastic, ten, twenty, 30 years ago?" I can see the words "golden age" floating above people's heads. I am not sure there ever was a golden age, but I think that we can reinvent ourselves, do better, and do better in different ways. I think trying to return to the past is always a mistake.

The Moderator: I think that has been a very full some answer to those questions and demonstrated that you do know quite a lot about these subjects, Louise. I hope that that has addressed those questions for the attendees that were asking them.

Questioner: The story of your career and your life so far, there is a sense that every so often you reinvent yourself. How you do that and are there any tricks and tips around that? Also, how to you find a balance the need for change with the naturally cautious approach that actuaries often have, partly through the way that they have been trained and qualified. How does that sit with this idea of experimentation and fast failure and continuing to move and adapt. How should students think about this, as people starting out in their actuary careers and still learning? In summary, what are the one or two things that you would encourage people to focus on when they are thinking about how to stay adaptive and be in a learning mode?

Dr Pryor: This may come as a surprise. I think of myself as very risk averse. I am not a risk taker. I do not think of myself as a risk taker. Now, I admit that looking back over my career history that is not the impression that I necessarily give. I have been very lucky. I have always made sure that I had some sort of safety net, for example, that I could go back to. At one stage when I tried something new, I cannot remember what was going on in the pensions world, but there were a lot of actuaries doing contracting work, basically going through individual cases on something or other, I cannot remember the details. I remember thinking, "Well, I am going to try this new thing, but if it doesn't work, I can always do that." There is always something I can do. I guess that is where the risk aversity comes in.

I like doing new things. I like learning about new things and usually how I have gone into a new field is by getting interested in it first. Interested enough to read about it, to learn about it and then thinking, "Well, actually this sounds really fascinating. I really want to get more into this and how can I do that?" People often ask me now, "I am an actuary. I don't know anything about climate change or sustainability, how can I get into it?" Well, the answer is to find out about it. 
There are a lot of resources on the IFoA website now, get involved with working parties if you can. I found volunteering is a fantastic way of learning about new things. Once you do that, once you learn more about it, you can start to add value because you can start to combine the new things you are learning about with your existing experience in new ways. Then you are offering value to people. That also provides a way of doing the experimentation, I suppose, by not necessarily making a career leap into the middle of nowhere, but making a volunteering leap if you like. It does not have to be through the IFoA, you can get involved with all sorts of other organisations to learn about new things. Is there anything I have missed there? Basically, I guess the thing is to try things out in a fairly controlled and harmless way before you make bigger changes.

Questioner: One of the topics that you did talk about in your address and we have not yet touched up, and it would seem remiss not to talk about it, is the pandemic, the thing that has changed all our lives in the last year, year and a half. The question that I have about this is, are you happy with the voice of actuaries within the pandemic? Has the profile and the role of actuaries in the pandemic has been where it should be? What do you think we have done well and what could and should we do better in this area?

Dr Pryor: Yes, this is a really interesting one. It is fairly clear that in many ways the IFoA is not set up for rapid response. In many ways, it possibly shouldn't be. For example, we had the COVID-19 Actuaries Response Group which was able to make rapid responses because it operated outside the IFoA bureaucracy. They did some fantastic work. They got together really quickly and they have been issuing bulletins for fifteen months now, responding to things as they have happened and they have had a very slick and effective way of doing that. I think they have really done well and have been a very good voice for actuaries during that time. That in fact turned out to work really well with ICAT, the IFoA COVID Action Taskforce, which has a slightly longer term perspective. We were setting up a lot of work-streams that were not responding within a matter of days, or weeks, but were looking at things over periods of months, or in some cases even years. That provided a good balance. The CMI, I thought, did really well during the pandemic, upping the frequency of its bulletins and making some very important points. Again, it was very predictable what they were saying in that they had a reasonably regular schedule of bulletins that all took the same form, but it provided a very good cumulative commentary on what was going on.

What I would like to see the IFoA learn from this would be a way of directly supporting small groups like the Actuaries Response Group, learning to recognise that not everything has to be done in the same way. To live with a plurality of groups, with varying levels of formal affiliation with the IFoA and just getting actuaries' voices out there is good and it does not all have to come with an official stamp.

Questioner: This is about the theme of diversity which again you spoke very passionately about. I think anyone who has followed your career to date will know it is a subject you care about a great deal. So, the distillation of questions that I want to ask you is, what are the areas that you think we - and the "we" in this, I think, is probably the IFoA and the profession - what are the areas you think we need to focus on next in the area of diversity? In particular, what practical progress will you want to see in your presidential year on this topic?

Dr Pryor: I think the first thing we need to do, the area we need to focus on is actually listening. Listening to the people involved and learning what their lived experience is. I know what my lived experience is, but I cannot second guess what other people's experience is. So, we have to listen to what people say and to take that seriously. That will help us think about what the barriers are to entry. Why don't people start in on the actuarial profession? Is it because they feel unwelcome? Is it because they feel they are not right? Is it because they do not see people like them? I don't know and I cannot guess. We have to find out. People often talk about this in terms of the pipeline. So we are talking about getting people in, sucking people into the pipeline. Then if we carry on with this rather unfortunate analogy, how do people leak out from the pipeline? Again, we might have ideas. I have ideas, I am sure you have ideas. But we actually need to listen to people and find out. That will then help us do things to address the problems that people identify. We need absolutely 
to collect data. As I said, we are a profession founded on data. We do not actually know what the situation is along many of these dimensions at the moment. So, we need to find out and that means collecting data. I would certainly like to see that during the next year.

I would also like to see more progress with our events. It has been brilliant. It is much better than it used to be. For many years, I used to go to sessional meetings, first in Edinburgh and then in London. I used to make sure that I stood up and made a contribution in every single sessional meeting I went to, whether I knew anything about the topic or not. I did that for two reasons. Firstly, to make sure that there was a least one woman speaking - and in many cases I was the only woman. Also, to lower the average age of people speaking. It was surprisingly recently that that stopped being true, the average age bit. We need to think about that. I look at the conferences we have put on. There are several at the moment, online conferences. You look at the front page, the advertisement page, beautiful, lots of pictures of all sorts of different people, different ages, different genders, different ethnicities, the whole lot and it looks fantastic. Then you go into the detailed programme and a surprising number of the sessions are still "manels" (male panels). They are still sessions with nobody but two or three white men presenting. This needs to change.

The Moderator: Louise, I like the practical things in there, the focus on data collection, which in a way is also a part of the listening. But I also love what I hope has been an encouragement to the attendees out there, who may represent all different kinds of diverse characteristics, to speak up hopefully when we are able to be in person again and also just to get involved in that sense of, as you did, in the sessional meetings. Bringing that different voice and as you say, changing the average age. It dawned on me as you were speaking Louise, that we may have broken a new IFoA record here in terms of being the first presidential address that has only had women in it. So, that might be a nice place for me to say sadly it is time for me to draw this to a close because we are pretty much out of time. It has been a fascinating walk through your passions and your priorities for society, for the actuarial profession and for the IFoA. You have also given us a real insight into how you will lead us through the coming year and the areas that we can expect to see you focusing on and speaking out about during that year. At our height we had about 330 attendees on the session and most of you have stayed with us right through. So, I would very much like to thank all of you.

Dr Pryor: Thank you. Thank you everybody.

Cite this article: Bogle K. (2021). A learning society by Dr Louise Pryor: Institute and Faculty of Actuaries Presidential Address 2021. British Actuarial Journal. https://doi.org/10.1017/S135732172100009X 